\title{
Fuel Property Effects on Burning Rate and Radiative Transfer from Liquid Pool Flames
}

\author{
JAYAVANT GORE and MICHAEL KLASSEN \\ Mechanical Engineering Department \\ The University of Maryland \\ College Park, Maryland 20742, USA
}

\author{
ANTHONY HAMINS and TAKASHI KASHIWAGI \\ Building and Fire Research Laboratory \\ National Institute of Standards and Technology \\ Gaithersburg, Maryland 20899, USA
}

\begin{abstract}
Measurements of burning rates and radiative heat loss fractions for pool flames burning a variety of fuels in pools of three sizes are reported. The data show significant effects of fuel type on burning rates. The radiative heat loss fractions of luminous flames are found to be relatively independent of sooting tendency. Measurements of monochromatic absorption and two-line emission intensities indicate that this insensitivity is due to the presence of large quantities of cold soot in heavily sooting flames.
\end{abstract}

KEYWORDS : Pool Fires, Radiation, Burning Rates

\section{NOMENCLATURE}

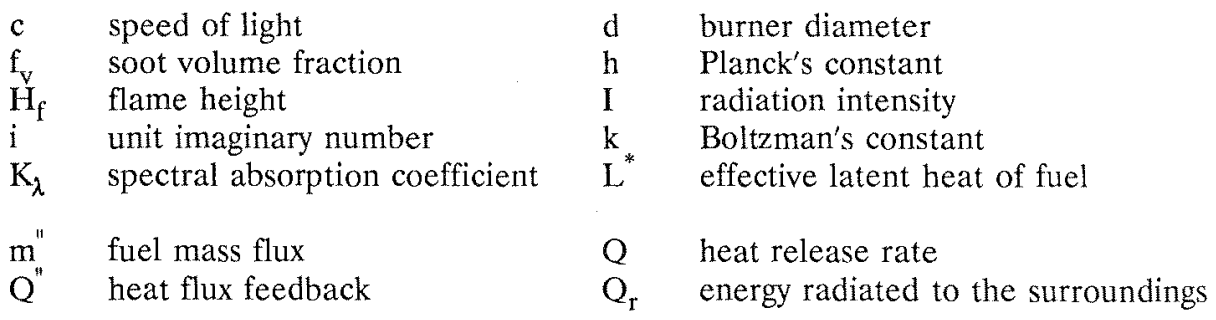


R

radius of axial heat flux

distribution measurements

$\mathrm{S}$ radiation path length

$\mathrm{T}$ temperature

$\mathrm{X}_{\mathrm{R}}$ radiative heat loss fraction

$\mathrm{Z}_{\max }$ maximum axial distance in

\section{Subscripts}

the calculation of $Q_{r}$

a absorption

e emission, equivalent

$\lambda$ monochromatic quantity at $\lambda$
$\mathrm{R}_{\mathrm{p}} \quad$ pool radius

$r^{p}$ distance of radiometer from

pool surface

$x, z$ axial distance from pool surface

$\lambda \quad$ wavelength

$r$ transmittance

b blackbody

o incident laser intensity

\section{INTRODUCTION}

Burning rates of objects on fire determine safe egress times, heating rate of surrounding objects and flame spread rates. Radiative heat flux from fires to surrounding objects determines the possibility of ignition, flame spread and flashover. Therefore, the knowledge of burning rates and radiative heat fluxes of flames has been sought since the early days of fire science [1].

Burning rate of liquid fuel in a pool flame configuration depends on the rate at which energy is transferred from the flame back to the fuel surface (heat feedback). Hottel [2] identified the heat feedback mechanisms as conduction, convection and radiation. Based on the data of Blinov and Khudiakov [3] for gasoline and diesel fuel fires, following inferences concerning the dominant heat transfer mechanism are stated in the literature [4]. Below a pool size of $10 \mathrm{~cm}$, conduction is important, between 10 $\mathrm{cm}$ and $30-50 \mathrm{~cm}$ diameter pools, convection is important and above these sizes radiation dominates the heat feedback. The size above which radiation becomes dominant is assumed to vary between $30-50 \mathrm{~cm}$ depending upon fuel type. Whether this limit is appropriate for heavily sooting fuels has not been examined. If the range is indeed appropriate then the reasons for the relatively narrow range of pool diameters over which fuels with vastly different sooting tendencies achieve the radiation dominated regime need to be understood.

In the conduction and convection dominated regimes, the mass flux at the surface of the liquid pool decreases with increasing diameter. In the radiation dominated limit the mass flux first increases with size and then reaches an asymptotic large-fire limit.

Measurements of radiative heat loss fraction, $X_{R}$, (defined as the fraction of the ideal heat of combustion that is radiated to the surroundings) for different fuels burning in the pool fire configuration have been reported in the literature $[4,5]$. The reported values of $X_{R}$ do not correlate with sooting tendency of the fuel. As an example, $X_{R}$ for heptane flames varies between 30 and $36 \%$ based on the data of Ref.[5] for pool sizes between 25 and $1000 \mathrm{~cm}$. Flames burning benzene, which has a higher sooting tendency, also radiate $34.5 \%$ and $36 \%$ of their chemical energy to the surroundings based on the data of Ref. [4] for pool sizes between 7.6 and $125 \mathrm{~cm}$. Although, the range of pool sizes 
is somewhat narrower for the benzene data, the lack of variation in $X_{R}$ with sooting tendency is surprising.

The purpose of the present paper is to study the burning rate and radiative heat loss fractions of fuels with different sooting tendencies. Eight fuels(methanol, ethanol, hexanol, heptane, methyl methacrylate (MMA monomer), toluene, styrene and an azeotropic mixture of toluene and ethanol) burning in two different pools (4.6 and 7.1 $\mathrm{cm}$ diameter) are considered. Four of these fuels (methanol, MMA, heptane and toluene) are also burnt in a larger diameter $(30 \mathrm{~cm})$ pool. Flames burning heptane and toluene are examined further using emission-absorption measurements to understand the low sensitivity of $X_{R}$ to sooting tendency.

\section{EXPERIMENTAL METHODS}

The $4.6 \mathrm{~cm}$ and $7.1 \mathrm{~cm}$ pools are uncooled pyrex containers and the $30 \mathrm{~cm}$ pool is a stainless steel pan cooled at the bottom. The liquid fuel is fed from the bottom by gravity feed through a flow control valve. The liquid level is monitored during the tests using a thermocouple mounted flush with the surface. The lip height is controlled to be approximately $0.5 \mathrm{~cm}$ for all the flames. The burning rates are measured using a load cell mounted under the fuel supply tank. The uncertainty in the load cell data is estimated to be $5 \%$.

The radiative heat flux distribution around the flames is measured using a calibrated, spectrally flat wide angle radiometer. The radiometer (facing towards the flame $)$ is traversed in the vertical direction at a distance " $R " ~(R=25,40$, and $160 \mathrm{~cm}$ for $4.6,7.1$ and $30 \mathrm{~cm}$ pools respectively) from the flame axis. The individual values of $R$ are selected to ensure that the entire flame is in the view of the detector at all measurement locations. The time-averaged radiation heat flux $\mathrm{q}(\mathrm{z})$ is measured starting from the plane of the pool $(z=0)$ and ending at a height at which $q(z)$ is approximately $10 \%$ of its maximum. The height $\left(Z_{\max }\right)$ at which $\mathrm{q}(\mathrm{z})$ would be negligible is estimated from the $q(z)$ curve by linear extrapolation. The radiometer (facing upward) is also traversed radially outward in the plane of the pool starting from the pool radius $R_{p}$ and ending at a radius of $R$. The time-averaged heat flux in the plane of the pool is designated $q(r)$. The total energy radiated to the surroundings $\left(Q_{r}\right)$ is obtained by numerically integrating the heat flux distribution over the semi-infinite cylindrical enclosure defined by the above measurements as:

$$
Q_{I}=2 \pi\left[R \int_{0}^{Z_{\max }} q(z) d z+\int_{R_{p}}^{R} r q(r) d r\right]
$$

The radiative heat loss fraction is obtained by dividing $Q_{r}$ by the ideal chemical energy release, $Q$, of the flames. The uncertainty in the radiative heat loss fraction measurements is estimated to be $10 \%$ based on repeated measurements and calibrations.

A sketch of the three line emission/absorption instrument is shown in Fig. 1. The 


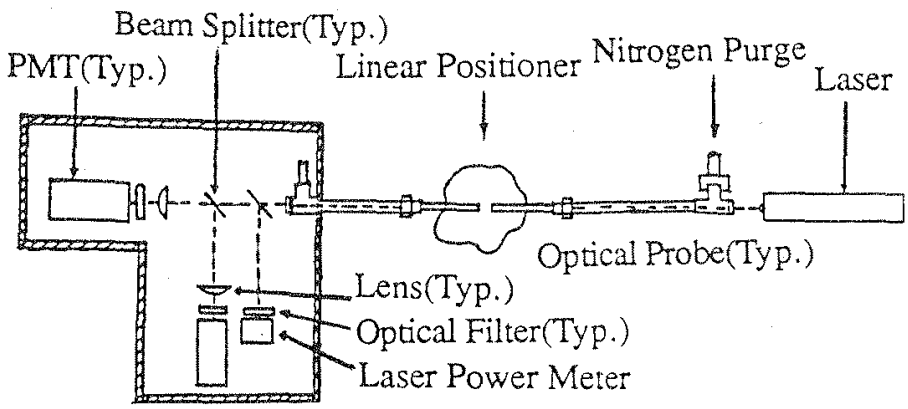

Fig. 1. A Sketch of the Three Line Absorption/Emission Apparatus

measurement technique is identical to that used by Sivathanu et al. [6]. Radiation intensities leaving the flame at two wavelengths $(900 \mathrm{~nm}$ and $1000 \mathrm{~nm})$ are measured. The light leaving the flames is collected by a $0.6 \mathrm{~cm}$ diameter $25 \mathrm{~cm}$ long stainless steel tube that has a nitrogen purge of $1 \mathrm{cc} / \mathrm{min}$. A second tube with identical purge flow serves as the cold background for the measurement and also as the guide for the incident $\mathrm{He}-\mathrm{Ne}(632 \mathrm{~nm})$ laser beam used for simultaneous transmittance measurements. The receiving tube ends in a light-tight enclosure containing the optics and the detectors. Two beam splitters are used to divide the light into three parts. Focussing lenses and line filters with $10 \mathrm{~nm}$ bandwidth on each channel complete the optics. The emission detectors are two photomultiplier tubes and the transmittance detector is a laser power meter. The incident laser power is monitored by an identical detector. All signals are sampled by a laboratory computer.

The ratio of the laser intensity after passing through the flame and the incident laser intensity is the transmittance through the flame:

$$
\frac{I_{\lambda}}{I_{\lambda O}}=e^{-\frac{K_{\lambda}}{\lambda} \int_{0}^{s} f_{\nu} d s}=\tau_{\lambda \vec{a}}(s)
$$

Under the present approximations, the transmittance is related to the volume fraction and refractive index of soot along the radiation path. The refractive index of soot is assumed to be independent of temperature and fuel type. There is controversy in the literature concerning the temperature dependence of refractive index of soot [6]. However, variation with temperature and fuel type is not seen for majority of the measurements. Therefore, a constant value $(1.55-0.56 \mathrm{i})$ of soot refractive index given by Dalzell and Sarofim [7] is used in the present study. With this value, $K_{\lambda}$ in eq. (2) is set at 4.89. The laser absorption measurements are used to calculate $\tau_{\lambda \text { a }}$ using eq. (2). 
Radiation intensities leaving the flame at the two wavelengths $(900 \mathrm{~nm}$ and 1000 $\mathrm{nm}$ ) are related to the distribution of soot volume fractions and temperatures along the narrow radiation path selected by the long receiving tube:

$$
I_{\lambda}=\int_{1}^{\tau_{\lambda}(S)} I_{\lambda b} d \tau_{\lambda}=\left(1-\tau_{\lambda e}(S)\right) I_{\lambda b}\left(T_{e}\right)
$$

where the local transmittance $\tau_{\lambda}$ (s) is defined by eq. (2) and $I_{\lambda b}$ is the black body intensity at the local temperature:

$$
I_{\lambda b}=\frac{2 h C^{2}}{\lambda^{5}\left(e^{h c / \lambda k T}-1\right)}
$$

It is noted that the intensity leaving the radiation path at the two emission wavelengths defined by eq. (3) depends on the soot volume fraction distribution along the path weighted by the local Planck's function $I_{\lambda b}$. The $K_{\lambda}$ at $900 \mathrm{~nm}$ is 5.33 and that at 1000 $\mathrm{nm}$ is 5.59 based on the refractive index for soot.

In order to compare measurements of radiation intensity obtained at various locations from flames burning different fuels, equivalent radiation temperature, $T_{e}$, and equivalent emission transmittance $\tau_{\lambda e}$ for the radiation path are defined as shown in eq. (3). Using the measurements of intensity at the two wavelengths, eqs. (3) are solved for $T_{e}$ and $\tau_{\lambda \mathrm{e}}$ assuming that the reciprocal wavelength dependence of eq. (2) is applicable to $\tau_{\lambda \mathrm{e}}$.

For an isothermal path, $\mathrm{T}_{\mathrm{e}}$ is equal to the actual temperature and $\tau_{\lambda \mathrm{e}}$ is identical to $\tau_{\lambda \mathrm{a}}$ after correcting for the wavelength dependence of the absorption coefficient. For a non-isothermal path, Sivathanu et al.[6] have found that $T_{e}$ is close to the peak soot temperature along the path. If a large portion of the soot particles along the path are at temperatures close to $T_{e}$, then $\tau_{\lambda_{\mathrm{a}}}$ and $\tau_{\lambda_{\mathrm{e}}}$ are similar. On the other hand, if $\tau_{\lambda \mathrm{a}}$ is much larger than $\tau_{\lambda \mathrm{e}}$, a large portion of the soot particles are at relatively low temperatures.

\section{RESULTS AND DISCUSSION}

Table 1 shows the measurements of mass burning rates, $m^{\prime \prime}$, and $X_{R}$ for the seventeen different flames. The mass burning rates are obtained by averaging the load cell measurements over a 3 minute period. The heat flux measured by the wide angle radiometer was also averaged for three minutes in order to estimate average $X_{R}$. To facilitate a discussion of these data, the effective heats of vaporization of the fuels $\mathrm{L}^{*}$, the ideal heat release rates $Q$, and the effective heat feedback to the fuel surface Q", are also tabulated. The ideal heat release rates are estimated from the average mass burning rates by applying conservation of energy to a chemical reaction involving complete oxidation of the fuel to $\mathrm{CO}_{2}$ and $\mathrm{H}_{2} \mathrm{O}$ by air. The heat feedback is evaluated 
Table 1: Burning Rate and Radiative Heat Loss Fraction Data

\begin{tabular}{|c|c|c|c|c|c|c|}
\hline$\overline{\text { FUEL }}$ & $\begin{array}{l}\mathrm{d} \\
\mathrm{cm}\end{array}$ & $\begin{array}{l}\mathrm{m}^{\text {na }} \\
\mathrm{g} / \mathrm{min}-\mathrm{cm}^{2}\end{array}$ & $\begin{array}{c}\mathrm{Q}^{\prime \prime} \\
\mathrm{kW} / \mathrm{m}^{2}\end{array}$ & $\overline{\mathrm{X}_{\mathrm{Ra}}}$ & $\begin{array}{l}\mathrm{Q} \\
\mathrm{kW}\end{array}$ & ${ }_{\mathrm{L}}^{\mathrm{b}_{\mathrm{L}} / \mathrm{Kg}}$ \\
\hline Methanol & $\begin{array}{l}7.1 \\
30\end{array}$ & $\begin{array}{l}0.079 \\
0.076\end{array}$ & $\begin{array}{l}16 \\
15\end{array}$ & $\begin{array}{l}0.2 \\
0.17\end{array}$ & $\begin{array}{l}1.16 \\
22\end{array}$ & 1200 \\
\hline Ethanol & $\begin{array}{l}4.6 \\
7.1\end{array}$ & $\begin{array}{l}0.083 \\
0.076\end{array}$ & $\begin{array}{l}14 \\
11\end{array}$ & $\begin{array}{l}0.2 \\
0.17\end{array}$ & $\begin{array}{c}0.6 \\
1.4\end{array}$ & 1021 \\
\hline Hexanol & 7.1 & 0.059 & 8.5 & 0.21 & 1.5 & 865 \\
\hline Heptane & $\begin{array}{l}4.6 \\
7.1 \\
30.0\end{array}$ & $\begin{array}{l}0.112 \\
0.138 \\
0.221\end{array}$ & $\begin{array}{l}9.1 \\
11 \\
18\end{array}$ & $\begin{array}{c}0.32 \\
0.27 \\
0.31\end{array}$ & $\begin{array}{c}1.4 \\
4.0 \\
116\end{array}$ & 482 \\
\hline MMA & $\begin{array}{l}4.6 \\
7.1 \\
30.0\end{array}$ & $\begin{array}{l}0.17 \\
0.15 \\
0.22\end{array}$ & $\begin{array}{l}13 \\
12 \\
17\end{array}$ & $\begin{array}{l}0.34 \\
0.33\end{array}$ & $\begin{array}{l}1.1 \\
2.4 \\
72\end{array}$ & 461 \\
\hline Toluene & $\begin{array}{l}4.6 \\
7.1 \\
30.0\end{array}$ & $\begin{array}{l}0.191 \\
0.242 \\
0.254\end{array}$ & $\begin{array}{l}16 \\
21 \\
22\end{array}$ & $\begin{array}{l}0.32 \\
0.31\end{array}$ & $\begin{array}{l}2.2 \\
6.7 \\
125\end{array}$ & 514 \\
\hline Styrene & $\begin{array}{l}4.6 \\
7.1\end{array}$ & $\begin{array}{l}0.195 \\
0.212\end{array}$ & $\begin{array}{l}17 \\
19\end{array}$ & $\begin{array}{l}0.31 \\
0.31\end{array}$ & $\begin{array}{l}2.2 \\
5.6\end{array}$ & 531 \\
\hline $\begin{array}{l}\left(0.3^{\mathrm{c}}\right. \\
\text { Toluene } \\
+0.7^{\mathrm{c}} \\
\text { Ethanol) }\end{array}$ & 7.1 & 0.102 & 15 & 0.27 & 2.2 & 863 \\
\hline
\end{tabular}

from the average mass burning rates by multiplying the latter by the effective latent heat $L^{*}$.

The first three fuels in Table 1 form nonluminous (methanol) or very weakly luminous (ethanol and hexanol) flames with radiation originating primarily from the gaseous product species. For identical pool size $(7.1 \mathrm{~cm})$, the burning rate for methanol is the highest with that of ethanol only slightly lower. The burning rate of hexanol is 
approximately $30 \%$ lower than that for methanol. This behavior is apparently surprising since the latent heat of methanol is highest of the three fuels and its heat of combustion is the lowest. As per correlations from the literature, its burning rate should be the lowest.

The heat feedback to the methanol surface is highest of the three alcohols. It is approximately twice that of the hexanol flames. An examination of the flame shapes and measurements of temperature profiles show that the methanol flames are close to the fuel surface and form a narrow neck towards the center. The resulting larger temperature gradients lead to enhanced heat transfer. The flames formed by hexanol on the other hand do not form a neck leading to lower temperature gradient at the surface and a lower burning rate. The present data are not sufficient to determine the relative contributions of flame radiation and convective heat feedback for the alcohol fuels. However, the surprising trend in the burning rates of the alcohol fuels highlights the need for the consideration of fuel structure in burning rate correlations.

The radiative heat loss fractions of all three alcohol fuels are between $17 \%$ and $21 \%$ for the different pools. The radiation is dominated by the infrared bands of carbon dioxide and water vapor.

The next four fuels listed in Table 1 form flames showing considerable yellow luminosity due to soot particles. Transmittance measurements[8] show that the propensity for soot increases in the order heptane-MMA-styrene-toluene. The sooting tendency of toluene and styrene is very similar. The burning rate of heptane increases continuously with pool size for the three pools studied here suggesting that even the 30 $\mathrm{cm}$ flame may not have reached the large fire radiation dominated limit. Similar behavior is observed for MMA.

In contrast to heptane and MMA, the data for toluene show that from $4.6 \mathrm{~cm}$ burner to the $7.1 \mathrm{~cm}$ burner there is an increase in burning rate and that the burning rate is approximately constant for the $7.1 \mathrm{~cm}$ and $30 \mathrm{~cm}$ burners. The first observation highlights the increase in burning rate caused by radiation heat feedback (conductive and convective components decrease with size). The second observation illustrates that the flames have reached the radiation dominated limit at $7.1 \mathrm{~cm}$ pool size. This size is much smaller than the $30 \mathrm{~cm}$ size limit stated in the literature for less sooting fuels. The data for styrene also show a similar trend. The results for the azeotropic mixture of ethanol and toluene show intermediate values for the burning rate as expected.

The radiative heat loss fractions $X_{R}$ for the four luminous fuels are in the range 0.27 to 0.34 with no systematic trend with sooting tendency. The values of $X_{R}$ and their insensitivity to sooting tendency are similar to the observations of $X_{R}$ for benzene flames by Burgess and Hertzberg[4] and those for heptane flames by Koseki and Yumoto [5]. To understand this somewhat surprising experimental fact, the structure of the $7.1 \mathrm{~cm}$ heptane and toluene flames is studied further using measurements of $T_{e}$, $\tau_{\lambda_{\mathrm{e}}}$, and $\tau_{\lambda_{\mathrm{a}}}$. Although, the toluene flames are dominated by radiation heat transfer, both flames have approximately similar convective components in their heat feedback 
based on their flame shape and necking tendency. Radiation heat flux from both flames consists of continuum radiation due to soot particles and band radiation due to product gases. In the following discussion, the contribution from gaseous species is assumed to be approximately equal for the two fuels in order to concentrate on the differences in soot radiation.

The mean emission temperatures for the two flames are plotted as a function of distance from the fuel surface in Fig. 2. As noted earlier, these temperatures are close to the peak temperatures along the diametric radiation path. Over approximately half of the flame height, the temperatures in the toluene flames are lower by approximately $200 \mathrm{~K}$ than those in the heptane flames. The adiabatic flame temperature (assuming complete combustion) for toluene is approximately $150 \mathrm{~K}$ higher than that for heptane. Thus the observed temperatures for toluene indicate incomplete and nonadiabatic combustion. Since $\mathrm{X}_{\mathrm{R}}$ for the two fuels are close, the differences in the temperatures can not be attributed to the differences in radiative cooling but are a consequence of the reduced combustion efficiency of toluene as compared to heptane.

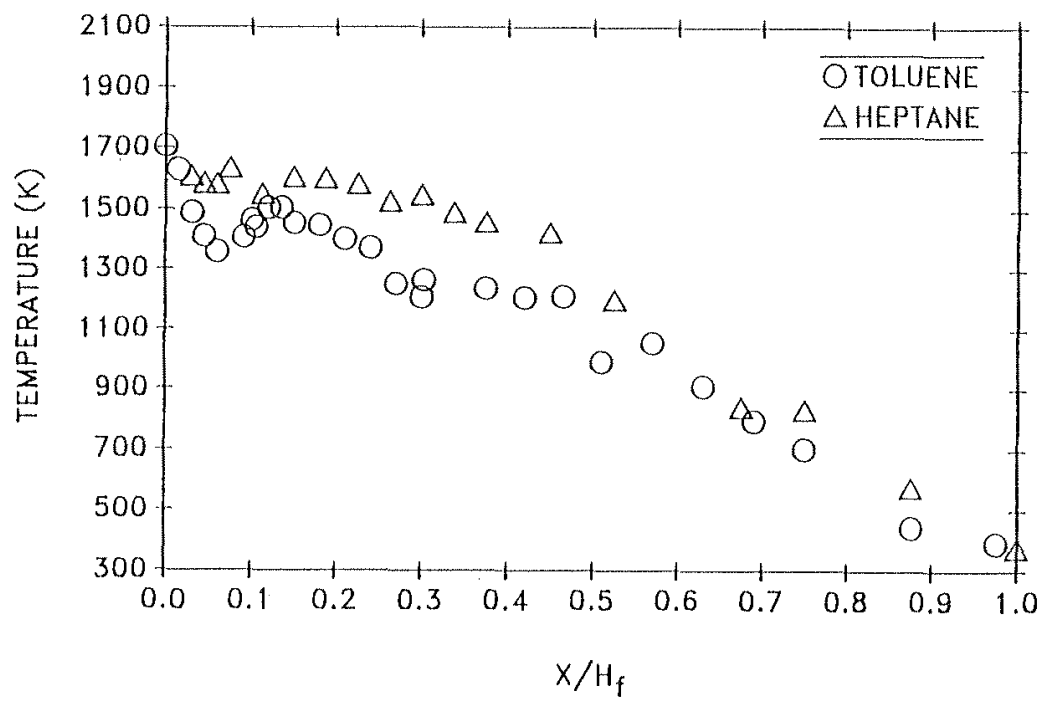

Fig. 2. Centerline Effective Radiation Temperatures for Toluene and Heptane Flames.

Figure 3 shows the absorption and emission transmittances for the two flames plotted as a function of axial distance. The measurements of $r_{\lambda_{a}}$ show that the toluene flames are optically thick with a transmittance less than $1 \%$ at certain locations and generally less than $30 \%$ at all locations. Based on both $\tau_{\lambda \mathrm{e}}$ and $\tau_{\lambda \mathrm{a}}$, the heptane flames are optically thin with transmittances greater than $70 \%$ for all locations. The difference between $\tau_{\lambda \mathrm{e}}$ and $\tau_{\lambda \mathrm{a}}$ for heptane flames is relatively small suggesting that large portion of the soot particles in this flame contribute to the radiation intensity. The 


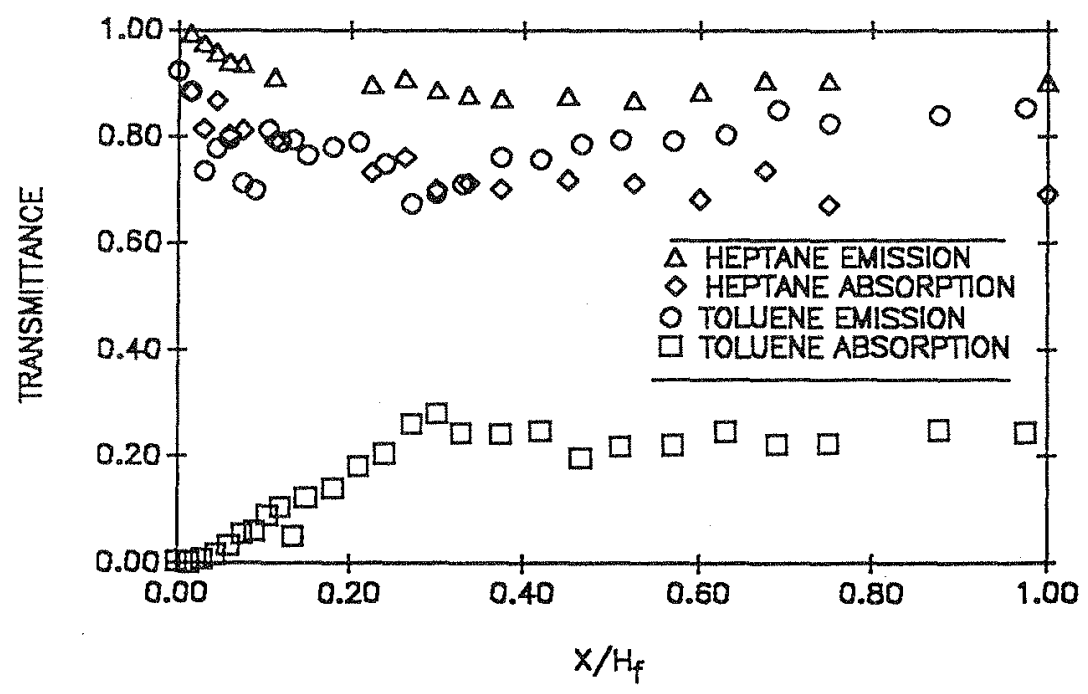

Fig. 3. Centerline Effective Emission and Absorption Transmittances for Toluene and Heptane Flames.

$r_{\lambda \mathrm{e}}$ for toluene flames is higher than $r_{\lambda_{\mathrm{a}}}$ by factors of between 4 to 10 . This observation suggests that a large portion of the soot particles in the toluene flames are at relatively low temperatures and do not contribute significantly to the radiation intensity. Sivathanu et al. [6] have experimentally and theoretically reached similar conclusions for heavily sooting acetylene/air flames. The existence of large quantities of cold soot in the toluene flames helps explain the relatively small increase in $X_{R}$ and heat feedback with sooting tendency.

\section{CONCLUSIONS}

(1) $\mathrm{X}_{\mathrm{R}}$ for the present alcohol fires are approximately $20 \%$. Effects of flame shapes on burning rates and $X_{R}$ that are not treated by existing correlations were observed.

(2) $X_{R}$ for the present luminous flames are approximately $30 \%$. The $X_{R}$ are independent of sooting tendency for luminous flames due to the presence of large amounts of cold soot particles.

(3) The burning rates of toluene and heptane flames show that the radiativelydominated limit is reached at vastly different sizes for the two fuels. For the $30 \mathrm{~cm}$ pool fires, the burning rates for the two fuels are similar in spite of the higher sooting tendency of toluene. This observations suggests that cold soot particles may exist in 30 $\mathrm{cm}$ toluene fires as well. 


\section{ACKNOWLEDGEMENTS}

The work of the authors from the University of Maryland is sponsored by the National Institute of Standards and Technology Center for Fire Research under Grant No. 60NANB8D0944. The emission/absorption instruments were developed under Grant No. CTS-8914520 from the National Science Foundation. Technical contributions of Dr. Y. R. Sivathanu are acknowledged.

\section{REFERENCES}

[1] deRis, J. , 1979, "Fire Radiation - A Review," Seventeenth Symposium (International) on Combustion, The Combustion Institute, Pittsburgh, pp. 1003-1016.

[2] Hottel H. C., 1958, "Certain Laws Governing the Diffusion Burning of Liquids," Fire Research Abstracts and Reviews, 1, pp. 41-44.

[3] Blinov V. I. and Khudiakov G. N., 1957, "On Certain Regularities of Diffusion Burning of Liquids," Dokl. Akad. Nauk. SSSR, 113, pp. 241-244.

[4] Burgess D. and Hertzberg M., 1974, "Radiation from Pool Flames," Heat Transfer in Flames, N. H. Afgan and J. M. Beer, eds., John Wiley, New York, pp. 413-430.

[5] Koseki H. and Yumoto T, 1988, "Air Entrainment and Thermal Radiation from Heptane Pool Fires," Fire Technology, pp. 33-47.

[6] Sivathanu Y. R., Gore J. P. and Dolinar J., 1990, "Transient Scalar Properties of Strongly Radiating Jet Flames," Heat and Mass Transfer in Fires and Combustion Systems, HTD Vol. 148, (W. L. Grosshandler and H. G. Semerjian, Eds.), ASME, New York, pp. 45-56, also Combust. Sci. and Tech., to appear in March 1991.

[7] Dalzell W. H. and Sarofim A. F., 1969, "Optical Constants of Soot and Their Application to Radiative Heat Flux Calculations," J. Heat Trans., Vol. 91, pp. 100-104.

[8] Gore J. P., Skinner S. M. and Gettings R. J., 1989, "Fuel Property Effects on the Radiation Properties of Laminar Diffusion Flames," Proceedings of the Twenty-Second Fall Technical Meeting, Eastern States Section of the Combustion Institute, Albany, NY, pp. 52.1-52.4. 